\title{
Rapid oil spill simulation within Ghana's coastal waters
}

\author{
Derrick Martin Adjei Sowa* \\ Department of Geography, Environment and Population, the University of Adelaide, SA 5005, Australia.
}

\begin{abstract}
Given the adverse externalities of hydrocarbon operations, particularly the impacts of oil spills environmental, political, cultural and socio-economic - the hypothetical simulations of oil spills enhances the study and appreciation of the trajectory and fate of spilled oil in the marine environment; so as to plan timely and cost effective clean-up responses and management strategies. This paper therefore presents the results of a rapid hypothetical simulation of oil spills in Ghana's coastal waters, and the clean-up technique(s) most applicable in the area. Using MIKE 21, tidal elevations were used as forcing to run the hydrodynamic model, after which a series of hypothetical simulations were conducted with the worst case scenario divulging both the trajectories of the oil slicks and the potential areas to be impacted. The simulation results closely matched the results highlighted in the Phase-1-Development EIA report of the Jubilee Field. Following the simulation, an assessment of the most viable clean-up technique was conducted. Given the geophysical state of the coastal system and the met-ocean conditions, the mechanical recovery method, complemented by bioremediation, is most applicable due to its marginal environmental impacts.
\end{abstract}

\section{Introduction}

The hydrocarbon industry has served the needs of people for decades, and the speedy industrialization in countries like China and India, coupled with the surge in the number of oil-powered machineries and equipment has initiated an increase in the demand for hydrocarbon products [1]. This increase in demand has caused an increased in hydrocarbon activities which has consequently increased the likelihood of oil spills in the oceans.

Despite the benefits obtained from hydrocarbons, the adverse impacts are devastating: Numerous news reports supported by anecdotal evidence have shown the overwhelming environmental externalities of hydrocarbons, with the most devastating incidence being the impacts of oil spills on the natural environment, human populations and other living creatures [2], [3]. Historic spill events such as the BP blow-out, the Exxon Valdez [4], Prestige, Amoco Cadiz, among others, have further highlighted the alarming effects of oil spills.

Given the assortment of adverse impacts, researchers have employed a multiplicity of strategies, particularly, the use of numerical models to simulate and predict the fate and transport of oil spills [3], [5]-[7]. Following the results obtained from these simulations, strategic measures are devised in order to effect timely and appropriate emergency responses [5].

This present study is thus, focused on conducting a series of hypothetical oil spills in Ghana's coastal waters to; (1) ascertain the trajectories of the oil slicks; consequently unearthing the areas likely to be impacted, and (2) establishing the clean-up technique(s) most applicable for the area.

\section{Study Area}

Ghana is located between latitudes $4^{\circ} 44^{\prime} \mathrm{N}$ and $11^{\circ} 15^{\prime} \mathrm{N}$ and longitudes $3^{\circ} 15^{\prime} \mathrm{W}$ and $1^{\circ} 12^{\prime} \mathrm{E}$; with a coastline that stretches for about $550 \mathrm{~km}$ [8]. In 2007, the country discovered commercial quantities of hydrocarbons at the Jubilee field within the West Cape Three Points Block in the Atlantic Ocean, and started oil production in 2010. The field is about $60 \mathrm{~km}$ offshore, between the Deep water Tano and West Cape Three Point blocks: approximately $75 \mathrm{~km}$ South-South-East (SSE) from the Ghana-Ivory Coast border, and $132 \mathrm{~km}$ South West (SW) of Takoradi. The Anchorage Area (i. e. the area dedicated for Crude Oil liftings) is located about $33 \mathrm{~km}$ North East (NE) of the Jubilee Field (i.e. around Lat $4^{0} 40^{\prime} \mathrm{N}$ and Lon $2^{0} 40^{\prime} \mathrm{W}$ ).

Temperatures within the area range between $25^{\circ} \mathrm{C}$ and $35^{\circ} \mathrm{C}$, with little variation all year round; mainly due to the country's position within the equatorial belt of the tropics. There are two main seasons; the wet and dry seasons [9]-[11], which are dictated by the seasonal variation of the Inter-Tropical Convergence Zone (ITCZ). The ITCZ is the area of convergence of the Tropical Maritime and the Tropical Continental Air Masses. The prevalent wind direction in the area is south-westerly.

The oceanographic conditions within Ghana's coastal waters are dominated by the Guinea Current at the surface, the Guinea Undercurrent and zones of coastal upwelling. The tidal regime in the area normally exhibits a consistent semi-diurnal pattern. Along the west coast of

Corresponding author: dmasowa@,outlook.com 
Ghana the tidal range is usually between $0.6 \mathrm{~m}$ and $1.2 \mathrm{~m}$ [12], and this produces a North Easterly tidal stream (for the flooding phase) and a South Westerly tidal stream (for the ebbing phase). Strong waves arrive from the open sea, and swells from the South Atlantic Ocean create stable surfs parallel to the coastline. On the average, the recorded significant wave height is $1.2 \mathrm{~m}$, with relatively long wave periods of between 10 and 15 seconds [13].

\section{Model Setup}

Mike 21was used in this study to conduct hypothetical spills in Ghana's coastal waters. The Flow Model (FM) module of Mike 21 was used to construct the hydrodynamic models while the Spill Analysis (SA) module was used to simulate the transport and fate of the oil. The SA module takes into account the essential parameters that affect the deformation and transport of the oil which occur in time and space - heat transport, evaporation, dispersion, dissolution and emulsification.

The SA module uses the particle tracking technique to calculate the concentration of oil and oil slick thickness in millimetres ( $\mathrm{mm})$. The advective component is calculated using the Lagrangian principle; making use of a linear interpolation for the time domain and a bilinear interpolation for the space domain. Interested readers may refer to [14] for further details.

The set of mathematical equations that govern the iterations are founded on the Navier-Stokes (N-S) equations, elaborated as follows;

$\frac{\partial u}{\partial x}+\frac{\partial v}{\partial y}+\frac{\partial w}{\partial z}=0$

Equation 1 shows the Continuity Equation - the mathematical expression of mass conservation.

$$
\begin{aligned}
& \frac{\partial u}{\partial t}+\frac{\partial u^{2}}{\partial x}+\frac{\partial u v}{\partial y}+\frac{\partial u w}{\partial z}=\frac{-1}{\rho} \frac{\partial p}{\partial x}+v\left(\frac{\partial^{2} u}{\partial x^{2}}+\frac{\partial^{2} u}{\partial y^{2}}+\frac{\partial^{2} u}{\partial z^{2}}\right) \\
& \frac{\partial v}{\partial t}+\frac{\partial u v}{\partial x}+\frac{\partial v^{2}}{\partial y}+\frac{\partial v w}{\partial z}=\frac{-1}{\rho} \frac{\partial p}{\partial y}+v\left(\frac{\partial^{2} v}{\partial x^{2}}+\frac{\partial^{2} v}{\partial y^{2}}+\frac{\partial^{2} v}{\partial z^{2}}\right)
\end{aligned}
$$

$$
\frac{\partial w}{\partial t}+\frac{\partial u w}{\partial x}+\frac{\partial v w}{\partial y}+\frac{\partial w^{2}}{\partial z}=\frac{-1}{\rho} \frac{\partial p}{\partial y}+v\left(\frac{\partial^{2} w}{\partial x^{2}}+\frac{\partial^{2} w}{\partial y^{2}}+\frac{\partial^{2} w}{\partial z^{2}}\right)-
$$$$
g
$$

Equations 2, 3 and 4 are the momentum equations (the essential fundamental laws of fluid dynamics).

$$
\begin{aligned}
& w=\frac{\partial \tau}{\partial t}+u \frac{\partial \zeta}{\partial x}+\frac{\partial \zeta}{\partial y}, \text { for } \mathrm{z}=\zeta(\mathrm{x}, \mathrm{y}, \mathrm{z}) \\
& u=v=w=0, \text { for } \mathrm{z}=-\mathrm{h}
\end{aligned}
$$

Equations 5 and 6 are the free surface condition and the bottom condition, respectively, of which both constitute the boundary equations. For the sign notations, $x, y$ and $z$ represent the spatial coordinates, $u, v$ and $w$ represent the three components of velocity, $\rho$ represents the density while $\mathrm{p}$ represents the pressure.

\subsection{Computational domain}

The computational domain was setup for the area between Lat $4^{0} 10^{\prime} \mathrm{N}$ and $5^{0} 15^{\prime} \mathrm{N}$ and from Lon $1^{0} 40^{\prime} \mathrm{W}$ to $4^{0} 05^{\prime} \mathrm{W}$, using $x y z$ data with resolution of 1 minute grids acquired from the Global Topography database of the University of California. This areal extent was chosen because it presents a larger model area for the expression of the physical conditions. Additionally, the size enables the accurate computation of wind surge, with good amount of grid points from both the Jubilee Field and the Anchorage Area.

In order to portray the real world conditions, all the boundaries (i.e. the Eastern, Western and Southern boundaries) were kept opened, while the coastal areas were smoothened to facilitate smooth flows along the water-land boundary, as illustrated in Figure 1.

\subsection{Boundary Conditions}

For the wind boundary conditions, twenty (20) years of Cross Calibrated Multi-Platform (CCMP) wind data with a resolution of $0.25^{\circ} \times 0.25^{\circ}$ was obtained from the Research Data Archive [15], for the Wet and Dry seasons - to match the climatic conditions in Ghana.

The wind field within these seasons were statistically assessed using Matlab. Around the Jubilee Field about 85\% of the wind originates from the SW direction and between $5 \%$ and $15 \%$ originates from the SE direction with relatively lower velocities. At the Anchorage Area, the dominant winds also originate from the SW, with a hand full from the SE direction. Within both areas, the predominant wind direction is southwesterly for both the Dry and Wet seasons. Approximately $94 \%$ of the wind speed is below $8 \mathrm{~ms}^{-1}$ while less than $5 \%$ is greater than $8 \mathrm{~ms}^{-1}$.

Along the coastal belt of Ghana, tides play pronounced roles in the geomorphology and transport processes, causing floods and other catastrophes via coastal erosion in certain areas along the coast [29][30]. Taking cognizance of the relevance of tides in the research area, the tidal situation was examined. Tidal elevations were therefore, predicted from the global tide package of Mike 21 Toolbox and applied to their respective boundaries; the eastern, western and southern boundaries, respectively. Upon a thorough examination it was observed that the tidal regimes at both the Jubilee field and the Anchorage Area were very similar 


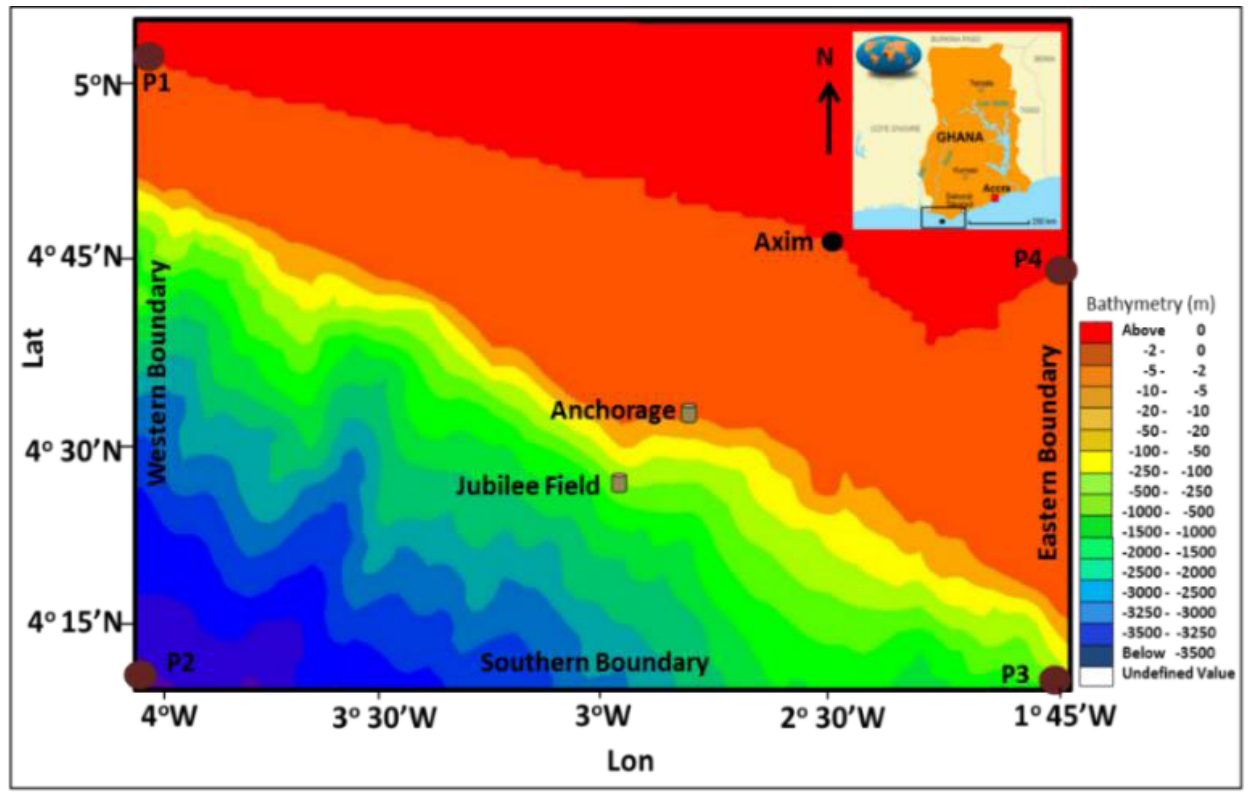

Fig. 1. Illustration of the computational domain.

\subsection{Model Validation}

In order to improve the suitability of the hydrodynamic model for the spill simulations, the model was calibrated by adjusting some calibration parameters. Tidal elevations were then extracted from a point within the model (i.e. Axim, Ghana) and were compared with the measured tidal elevations. Following a series of adjustments, the correlations between the modelled and measured tidal elevations were in reasonable agreement, with slight distortions in their relative elevations (Fig. 2).

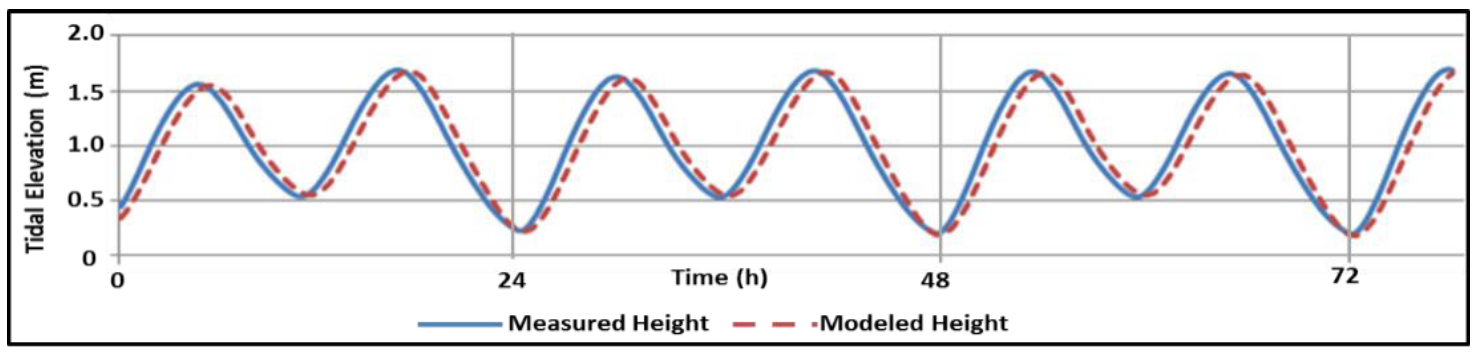

Fig. 2. Comparison of the Measured and Modeled tidal elevations at Axim.

\subsection{Oil spill simulation cases}

Due to the marginal tidal difference between the wet and the dry seasons the wet season was chosen since comparatively, it exhibited slightly higher values. A simulation period of 7 days (i.e. 168 hours), consistent with periods of spring tides was employed. This choice was made to reflect the higher than average tidal elevations and currents that characterize spring tides.

With regards to the range of the wind speeds experienced in the research area, the simulations were run using wind speeds of $2 \mathrm{~ms}^{-1}, 5 \mathrm{~ms}^{-1}$ and $10 \mathrm{~ms}^{-1}$. For the wind directions, winds from West-South-West (WSW), South-West (SW) and South-South-West (SSW) directions were applied. The simulations were run for 168 hours from both the Jubilee Field and the Anchorage Area.

\section{Results of the hydrodynamic model}

Figure 3 depicts the dominant direction of the tidal current, which drifts between the NE-NNE direction during the flood phase and SW-SSW direction during the ebb phase (Fig. 3). The velocities of the tidal current, as observed, varied between $0.01 \mathrm{~ms}^{-1}$ and $0.08 \mathrm{~ms}^{-1}$, barely reaching $0.1 \mathrm{~ms}^{-1}$.

As expected, the velocities of the tidal current recorded offshore were very minute [16], with maximum speeds recorded closer to the coastal belt. As a result of the sea bed resistance and the interaction between the tidal current and the coast, the velocity of the tidal current drops as it drifts into shallow waters. This phenomenon progressively creates a coastal boundary layer close to the shoreline. 


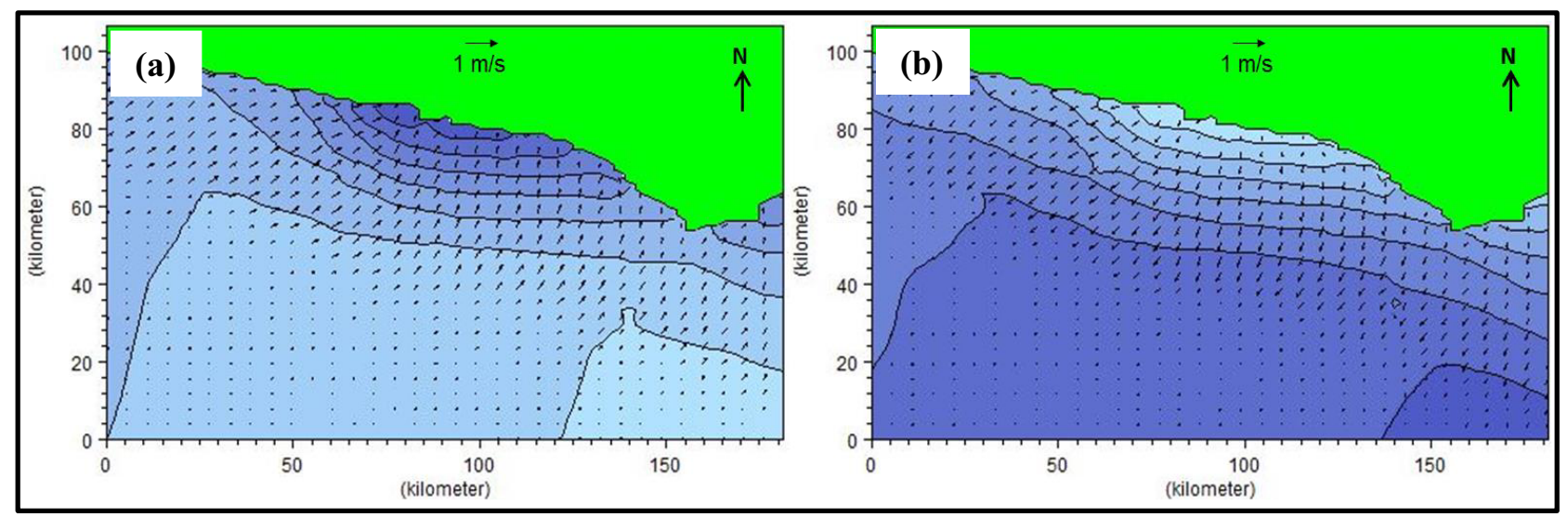

Fig. 3. Net direction of the tidal current; (a). Flood phase and (b). Ebb phase.

\subsection{Oil spill simulation results}

Using the Jubilee Field as the source, it can be seen in Figure 4 that the wind speeds of $2 \mathrm{~ms}^{-1}$ and $5 \mathrm{~ms}^{-1}$ presented no case of oil beaching. Nevertheless, $10 \mathrm{~ms}^{-1}$ winds from the West-South-Westerly direction resulted in oil beaching between two and three days (i.e. just before the $72^{\text {nd }}$ hour).

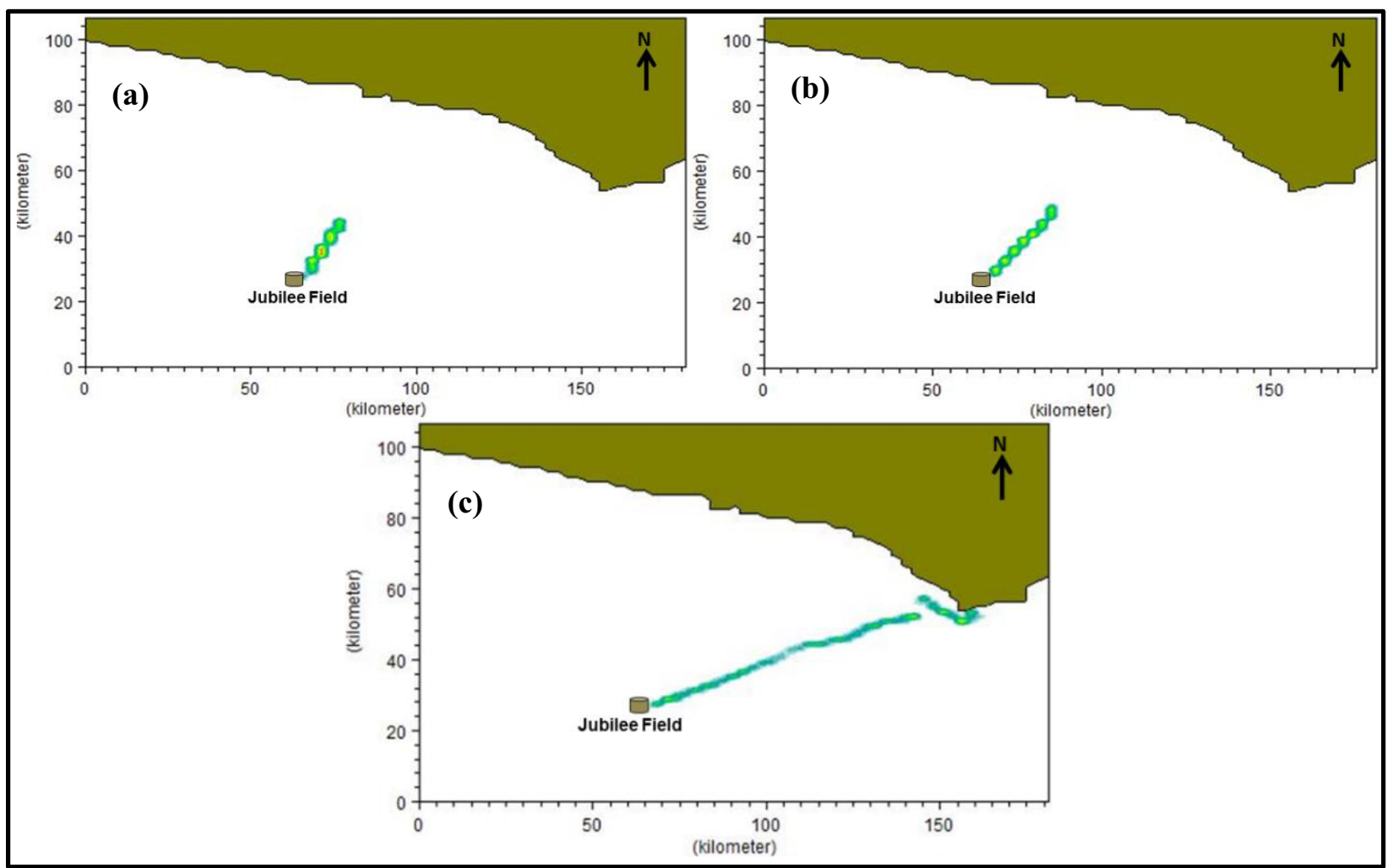

Fig. 4. Slick trajectories under wind speeds of (a). $2 \mathrm{~ms}^{-1}$, (b). $5 \mathrm{~ms}^{-1}$ and (c). $10 \mathrm{~ms}^{-1}$ in SSW, SW and WSW directions respectively.

Specifying the spill source at the Anchorage Area (Fig. 5), $2 \mathrm{~ms}^{-1}$ and $5 \mathrm{~ms}^{-1}$ winds from all directions didn't reach the coast. Nonetheless, the $10 \mathrm{~ms}^{-1}$ West-South-
Westerly winds resulted in oil beaching in two days; spreading laterally towards the eastern direction. 


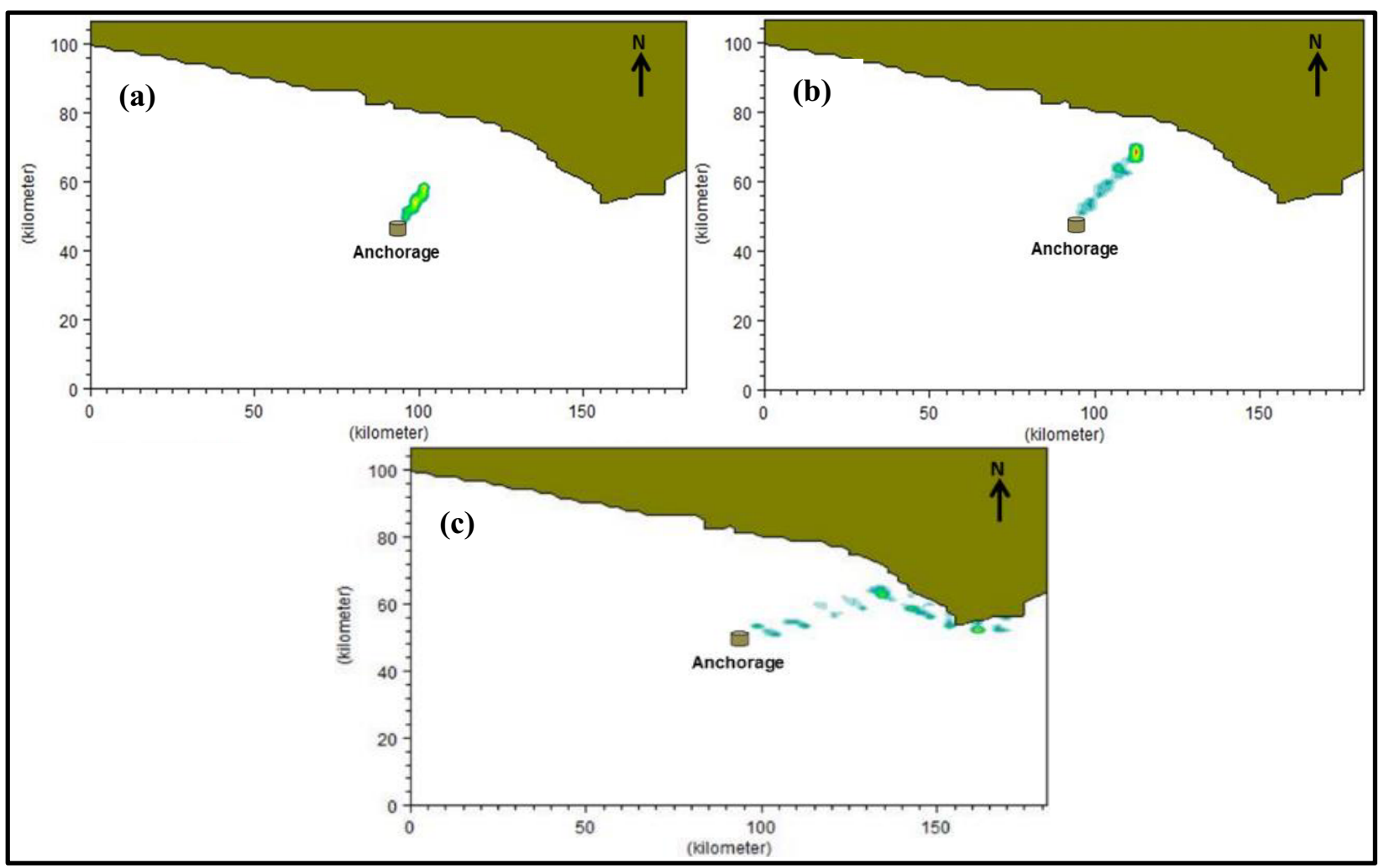

Fig. 5. Slick trajectories under wind speeds of (a). $2 \mathrm{~ms}^{-1}$, (b). $5 \mathrm{~ms}^{-1}$ and (c). $10 \mathrm{~ms}^{-1}$ in SSW, SW and WSW directions respectively.

\subsection{Areas likely to be impacted by a potential spill}

Similar to the areas noted in the Phase-1-Development EIA report of the Jubilee Field, the spill results have demonstrated that in the event of an oil spill accident, the principal areas that are likely to be affected are mainly the coastal communities located west of the Cape Three Points (i. e. the Nzema East Municipal) and a few coastal communities in the Ahanta West District (Fig. 6).
Sensitive features such as the wet lands, tidal floodplains and local hydrological bodies within these areas will be under potential threat. Wet lands such as the mouth of River Ankobra situated between Axim and Asanta in the Nzema East Municipality faces the threat of oil contamination.

Furthermore, fish species that are found in the Ehnuli and Amansure lagoons are very sensitive to oil spill effects. As a result, any case of oil spill will have devastating

effects.

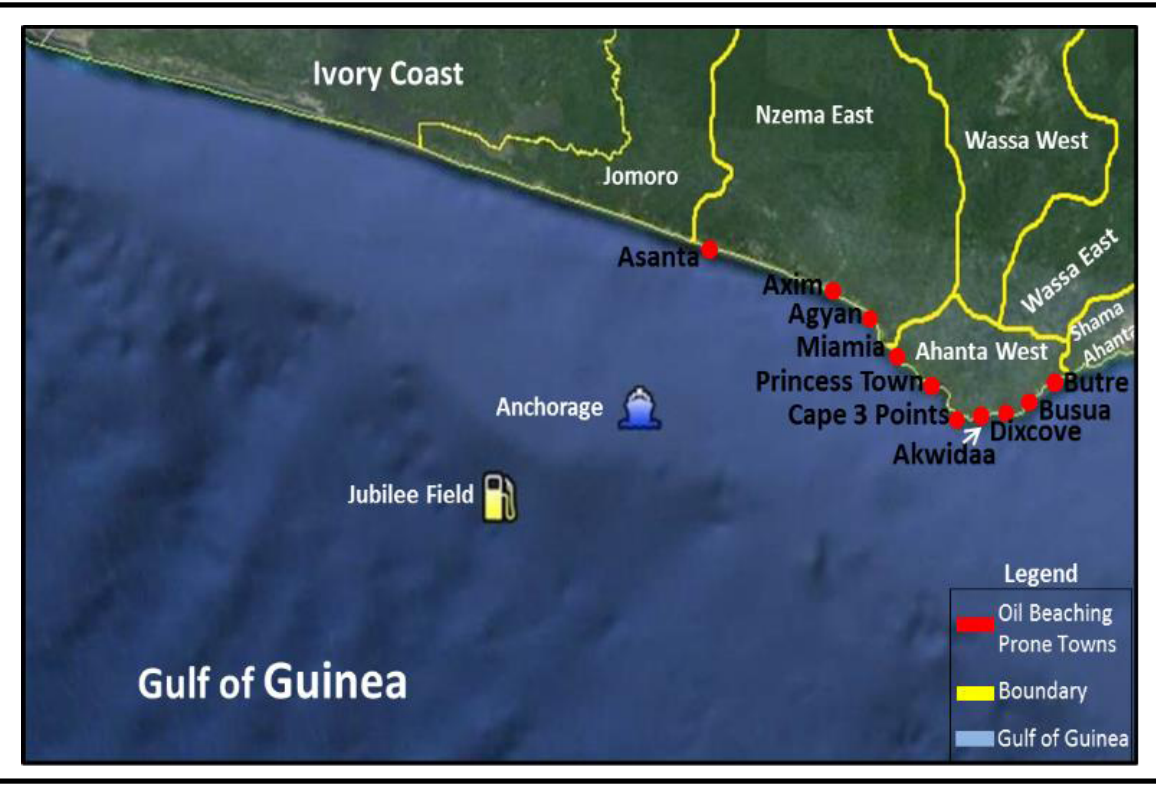

Fig. 6. Areas likely to be affected by possible oil spill. 


\section{Discussion}

Given the climatic condition of Ghana [11], [17], any small spill would have a significant portion of the oil vaporized. The chemical properties of the Jubilee Crude make it impossible for small spills to reach the shore especially when the spill occurs at either the Jubilee Field or the Anchorage Area. In addition, despite the fact that the surface currents [18], and the prevalent winds within the research area are benign in the dry season (i.e. November to February); the latitudinal displacement of the ITCZ [19], [20], influences the total drift of the oil slick. During this period the ITCZ positions itself within the lower latitudes enabling the Tropical Continental Air Masses to enter deep into the offshore environment. As they approach the ITCZ their travel velocities decline. Deep offshore however, the Tropical Maritime Air Masses dominate with a relatively higher velocities. The total drift of the oil slick is thus, mainly under the influence of the Tropical Maritime Air Mass till it gets closer to the coast where it starts to experience the effect of the Tropical Continental Air Mass. The TCAMs at this point tend to retard the travel velocity of the slick, consequently impeding the overall ability of the slick to make it to the shore.

The same phenomenon applies to the other spill scenarios, however, for the simulation period (i. e. June) in the other cases, the position of the ITCZ moves into higher latitudes [21], around latitude $5^{0} \mathrm{~N}$ [20]. The Prevailing TMAMs have higher spatial coverage, thus, propel the slick farther towards the shore. The increase in wind speed (i.e. from $2 \mathrm{~ms}^{-1}, 5 \mathrm{~ms}^{-1}$ to $10 \mathrm{~ms}^{-1}$ ) compensates for the increased travel distances of the oil slicks - getting much closer to the shore and even beaching (Figs. 4b, 4c, 5b and 5c). Further comparing Figures $4 \mathrm{c}$ and $5 \mathrm{c}$; it can be detected that the areal coverage of the oil slick is larger when the spill source is specified at the Anchorage Area than when it's specified at the Jubilee Field. This is mainly due to the sustained effects of wind forces, tidal effects and the total amount of exposure to the sunlight that gives way to evaporative losses.

With regards to the wind conditions applied, it can be noted that the lowest and typical wind conditions barely give way to oil beaching. The maximum winds (which can be perceived as the worst case winds) however, are what gives way to oil beaching cases; as per the simulation results.

The net direction maintained by the oil slick is largely as a result of the applied wind conditions, with little effect from the ambient tidal current. The tidal current however, affects the direction of the slick by creating slight back and forth movements of the slick.

The orientation of the coast, weak tidal stream and the effect of the prevalent winds gradually create an eastward lateral spread of the oil slick.

Having demonstrated that Ghana's coastal line is not immune to oil beaching, it is imperative that strategic measures are put in place so as to enhance convenient and timely responses should any spill accident occur. The ensuing section therefore briefly explores some of the available emergency response techniques; emphasizing the option(s) most applicable to Ghana's setting.

\section{Clean-up Technique Most Applicable to Ghana's Coastal System}

Immediately a spill accident takes place the principal emergency response goals are to prevent the spill from reaching the shore, to reduce the impact on marine life and to quickly degrade the oil that may not be recovered. To achieve these goals, some response techniques and clean-up measures are employed [5].

Presently, there are about four main techniques that are employed in cleaning up oil spills [5], [22], [23]. These include the Mechanical Recovery technique, Bioremediation, In-situ Burning and the use of Dispersants. Each of these techniques have their own advantages and shortcomings which pertains to convenience, ease, scalability, environmental externalities and cost [24].

Whereas the in-situ burning technique results in the creation of excessive toxic smoke, which could drift landwards and affect people residing in peripheral communities, the use of chemical dispersants to increase the rate of dispersion of the slick, according to Merlin, (2005) [25], poses severe health risks on the local residents; especially when the dispersants are applied in shallow waters.

In using chemical dispersants, the chemicals within the dispersants initiate the breakup of the homogeneous oil slick into several tiny droplets which easily dilute and get entrained into the water column, subsequently degraded by micro-organisms in the water. As noted by Swannel and Daniel (1999), [26], the use of chemical dispersants is effective provided the right amount is applied under the right conditions.

It will suffice to note that even though there is a policy that permits the use of dispersants in clean-up operations in Ghana, the technique is secondary to the mechanical recovery technique; largely due to the potential environmental impacts [24]. Upwelling processes within Ghana's coastal system that occur within certain periods may cause the resurfacing of dispersed chemicals, and given the increased level of fishing activities along the coast during such periods, this is likely to cause significant health problems. Also, with regards to the presence of some small intertidal flats and other sensitive ecological assets, the use of dispersants in the study area may not always be practical, particularly when the oil slick is within a close proximity to the shoreline.

The mechanical recovery technique, on the other hand seems applicable to the Ghanaian setting since its operational competences correspond well with the geography, meteorology and the oceanic conditions in the area. More to this, while the weighted advantages of this technique supersede the others, it also tends to possess marginal environmental impacts when compared to the other techniques. For instance the use of containment booms can be employed not only as a responsive means to contain oil after a spill, but can also 
be used as a preventive measure. This technique also affords the use of Oil Skimmers and hydrophobic sorbents for the conversion of the liquid crude to a semisolid state; which enhances its complete removal from the sea [27].

For improved clean-up activities however, particularly in ecologically sensitive zones, manual methods such as the use of sorbents and bioremediation techniques may both be used to complement the competency of the mechanical clean-up technique. Even though heavy crude oils are less amenable to the process of biodegradation due to the presence of asphaltene and resin compounds [28], the oil produced in the Jubilee Field is Light Crude, whose aliphatic components are highly amenable to hydrocarbon bioremediation [28]. The technique often produces intermediate/finished composites that are unlikely to cause significant environmental damage.

\section{Conclusion}

The results of this study, which are quite similar to those highlighted in the Phase-1-Development EIA report of the Jubilee Field, have shown the spatio-temporal variations and distributions of hypothetical oil spills in the Ghana's coastal waters; further divulging that the western portions of Ghana's coastline are not immune to oil beaching. While the prevalent winds was the principal contributing factor in the landward trajectory of the oil slick, the combined effect of the tidal current, the orientation of the coast and the persistent winds create the eastward lateral spread of the oil slick once it reaches much shallow waters.

The geophysical state of the coastal system as well as the met-ocean processes have also shown that the most applicable clean up technique is the mechanical technique due to its marginal environmental impact. For improved clean-ups however, the technique of hydrocarbon bioremediation may be used to complement the competency of the mechanical recovery technique. In some controlled cases chemical dispersants may be used, but this technique remains secondary to the mechanical clean up techniques.

While this study has divulged the vulnerability of sections of Ghana's coastline to oil beaching it is prudent that the government regulatory agencies that are charged to ensure the safety of the natural environment, as well as those that are charged to regulate hydrocarbon activities, are up and doing. In line with this, subsequent studies will examine the environmental regulatory system used to govern petroleum activities in Ghana's upstream petroleum industry so as to identify and explore the myriad complexities surrounding the environmental behaviours of petroleum companies and the exercise of regulatory functions by government regulators who are charged to ensure environmental protection in the country's upstream petroleum industry.

\section{Acknowledgement}

The author acknowledges the assistance of the reviewers, whose constructive comments have contributed immensely to the success of this paper. Individual support from friends and colleagues is greatly appreciated.

\section{References}

1. D. O. Mañe, "Emergence of the Gulf of Guinea in the global economy: Prospects and challenges," (2005).

2. K. Y. H. Gin, M. K. Huda, W. K. Lim, and P. Tkalich, "An oil spill-food chain interaction model for coastal waters," Mar. Pollut. Bull., vol. 42, no. 7, pp. 590-597, (2001).

3. P. Vethamony, K. Sudheesh, M. T. Babu, S. Jayakumar, R. Manimurali, A. K. Saran, L. H. Sharma, B. Rajan, and M. Srivastava, "Trajectory of an oil spill off Goa, eastern Arabian Sea: Field observations and simulations," Environ. Pollut., vol. 148, no. 2, pp. 438-444, (2007).

4. S. Graham, "Environmental Effects of Exxon Valdez Spill Still Being Felt - Scientific American," (2003).

5. M. Fingas, The basics of oil spill cleanup. CRC Press, (2012).

6. P. Tkalich, K. Huda, and K. Y. Hoong Gin, "A multiphase oil spill model," J. Hydraul. Res., vol. 41, no. 2, pp. 115-125, (2003).

7. M. Reed, Ø. Johansen, P. J. Brandvik, P. Daling, A. Lewis, R. Fiocco, D. Mackay, and R. Prentki, "Oil spill modeling towards the close of the 20th century: overview of the state of the art," Spill Sci. Technol. Bull., vol. 5, no. 1, pp. 3-16, (1999).

8. A. K. Armah and D. S. Amlalo, "Coastal zone profile of Ghana: Accra, Gulf of Guinea large marine ecosystem project. Ministry of Environment," Sci. Technol. Accra, (1998).

9. M. A. Mensah, "The influence of climatic changes on the coastal oceanography of Ghana," (1991).

10. C. A. Biney, "A review of some characteristics of freshwater and coastal ecosystems in Ghana," Hydrobiologia, vol. 208, no. 1-2, pp. 45-53, (1990).

11. K. A. Koranteng, "The impacts of environmental forcing on the dynamics of demersal fishery resources of Ghana." University of Warwick, (1998).

12. K. Appeaning Addo, P. N. Jayson-Quashigah, and K. S. Kufogbe, "Quantitative Analysis of Shoreline Change Using Medium Resolution Satellite Imagery in Keta, Ghana," Mar. Sci., vol. 1, no. 1, pp. 1-9, Aug. (2012).

13. K. A. Addo and M. Adeyemi, "Assessing the impact of sea-level rise on a vulnerable coastal community in Accra, Ghana: original research," Jamba J. Disaster Risk Stud., vol. 5, no. 1, pp. 1-8, (2013).

14. DHI, “Mike 21," 2018. [Online]. Available: http://manuals.mikepoweredbydhi.help/2017/MIKE 21.htm. [Accessed: 05-Nov-2018].

15. DECS-NCAR, "Computational and Information Systems Laboratory - Research Data Archive," 
(2014). [Online]. Available: https://rda.ucar.edu/datasets/ds744.9/.

16. D. A. Ross, Introduction to oceanography. Appleton-Century-Crofts New York, (1970).

17. C. Roy, "The Côte d'Ivoire and Ghana coastal upwelling dynamics and changes," (1995).

18. C. Colin, "Coastal upwelling events in front of the ivory-coast during the focal program," Oceanol. $a c t a$, vol. 11, no. 2, pp. 125-138, (1988).

19. B. Fontaine, S. Janicot, and P. Roucou, "Coupled ocean-atmosphere surface variability and its climate impacts in the tropical Atlantic region," Clim. Dyn., vol. 15, no. 6, pp. 451-473, (1999).

20. B. Sultan and S. Janicot, "Abrupt shift of the ITCZ over West Africa and intra - seasonal variability," Geophys. Res. Lett., vol. 27, no. 20, pp. 3353-3356, (2000).

21. F. Hourdin, I. Musat, J.-Y. Grandpeix, J. Polcher, F. Guichard, F. Favot, P. Marquet, A. Boone, J.-P. Lafore, and J.-L. Redelsperger, "AMMA-model intercomparison project," Bull. Am. Meteorol. Soc., vol. 91, no. 1, pp. 95-104, (2010).

22. Itopf, "Fate of marine oil spills," Itopf, no. 2, pp. 1$8,(2002)$
23. D. Dave and A. E. Ghaly, "Remediation technologies for marine oil spills: A critical review and comparative analysis," Am. J. Environ. Sci., vol. 7, no. 5, p. 423, (2011).

24. D. S. Etkin, "Factors in the dispersant use decisionmaking process: Historical overview and look to the future," in Proceedings of the 21st Arctic and Marine Oilspill Program Technical Seminar, pp. 281-304 (1998).

25. F. X. Merlin, "Using dispersant to treat oil slicks at sea," Airborne Shipborne Treat. Response Manual. Sect. D. Monit. Assessment. Prep. French Navy Minist. Ecol. Sustain. Dev. by CEDRE. Brest, Fr. December. 54pp, (2005).

26. R. P. J. Swannell and F. Daniel, "Effect of dispersants on oil biodegradation under simulated marine conditions," in International Oil Spill Conference, vol. 1999, no. 1, pp. 169-176 (1999).

27. M. O. Adebajo, R. L. Frost, J. T. Kloprogge, O. Carmody, and S. Kokot, "Porous materials for oil spill cleanup: a review of synthesis and absorbing properties," J. Porous Mater., vol. 10, no. 3, pp. 159-170, (2003).

28. R. M. Atlas, "Effects of temperature and crude oil composition on petroleum biodegradation," Appl. Microbiol., vol. 30, no. 3, pp. 396-403, (1975). 